\title{
DIFFERENTIATION: ADDRESSING BIAS INVOLVED IN TEACHER CONFLICT WITH STUDENTS
}

\author{
Rebecca J. Reynolds* and Marjenah Gilpatrick \\ Grand Canyon University, United States
}

\begin{abstract}
The research purpose for this Literature review is to explore, and differentiate possible solutions for teacher-student conflict originating from teacher or student bias. The objective of this phenomenological literature review: to explore the reflective practice of teachers in relationship to differentiating possible solutions for teacher-student conflict created out of bias. The methodology includes aligning and subjugating five phenomenological areas of possible bias: personal choice, emotions, situations children experience, slow approaches to learning, and teacher reflection. A literature gap leaves research questions like; How does bias influence conflicts between teachers and students? How can reflection and differentiation make a difference in the bias that influences teacher conflicts with students? Reflection of personal biases allows educators to accept students' values and unique perspectives, creating an example of non-biased educational environment. The exploration of teacher reflective practice, and attitudes; understanding personal biases allows for educators to accept students' values and unique perspectives. The implications of educators' awareness, reflection and responsiveness, to diverse student populations; includes students' socialemotional needs, trauma impact, cultural and economic backgrounds, and advocacy for equity and equality. Educators need to face personal biases recognizing the impact in the classroom where inequity and inequality can persist, influencing the development of conflict between teacher and student. The recommendation is for further phenomenological research on teacher and student opinion relating to how bias impacts teacher-student conflict, conducted in a current day environment, and continued for further assessment value.
\end{abstract}

\section{Introduction}

By utilizing non-biased differentiation and restorative tools in conjunction with reflective practice, teachers broaden the lens through which they view the world. They are then able to engage as advocates and activists for students and operate from a non-biased understanding that overwhelms many classrooms.

Bias prevention in the form of "Cultural responsivity" can be traced to the Civil Rights Movement of the 1960's. Reeves (2002) explained that the 1964 Civil Rights Act set the precedent for many institutions of higher education to offer courses and programs relating to ethnic studies and multicultural education, lending an example to create a non-biased educational environment. Administers of school districts that house grades kindergarten through 12th grade, focused on implementing processes that would promote multicultural environments on campuses. These included teachers' attitudes, instructional materials, assessment methods, counseling approaches, and teaching styles (Banks, 2006), without acknowledging teacher or student reflections, or teacher or student bias'. Because of the link between language and culture, and to address equity of instruction, the United States Congress passed The Bilingual Education Act of 1968, which provided federal funding to local school districts to encourage the implementation and incorporation of native language instruction in their respective curriculums.

By creating a linguistic requirement, tensions between educators and students can possibly show signs of relief in conflict between teacher and student created by bias, as attitudes and stereotypes, which are triggered "unconsciously and involuntarily" (Flannery, 2015) by both teacher and student. 
According to Dutro and Moran (2005), the landmark Supreme Court case, Lau v. Nichols (1974) made the language policy a federal one. The government, however, did not set any specific mandates for implementing the Lau legislation. That task was assigned to each state and individual school district. Berube (2000) stated that the only directive that the states and school districts received was to "take appropriate action to overcome language barriers that impede equal participation by its students in its instructional programs" (as cited in Reeves, 2002, p. 14). The Congress then passed the Equal Educational Opportunity Act (1974). In order to enforce this act, the federal Office for Civil Rights, along with the federal courts applied a three-step test to ensure that schools provide research-based programs viewed as theoretically sound by experts in the field; (1) have adequate resources to implement the program, (2) implement standards and procedures to evaluate the program, and (3) modify any program that fails to produce results.

Presentations on how to build cultural bridges that embrace diversity instead of shaming will have a direct impact on educators' ability to keep students engaged (University of Kansas, 1994-2020). Relationships can then be built on a foundation of respect and accountability, communication can have a new effectiveness because it can be calming instead of challenging, (Bridgewater State University, 2015) bringing teacher and student, reflections to the surface.

Teacher reflections can assist in bias prevention and cultural considerations. Reflective practice can be a tool to create strategies to learn about each individual child, especially in older age groups where there are more children per teacher. Time, to many students, and bias, can prevent teachers from learning about each student. Finding and using creative teaching resources can be very helpful in understanding each student's individual needs. Stressors and bias experienced by students, not identified by teachers, may have an impact on any conflict between teacher and student. Students experiencing things like developmental delay in the early years, depression, grief, etc.

Another example is evident in the work of Dr. Steve Constantino author of Engaging Every Family - Five Simple Principles, whose research found that when schools meaningfully engage with families using culturally competent practices; methods of engagement are simple and easily implemented based on perceptions of school's whose ambience is welcoming and communicating using language and phraseology that is recognizable to ethnic students and their parents.

Recognizing one's own bias is only the first step. The next step in this research consists of taking a look at how teacher reflection and bias impact conflict between teachers and students. More information is needed concerning how teachers develop possible bias (Gershenson, etal, 2015); but does this possible bias impact conflict with students in their classrooms? "Implicit biases are defined by the Kirwin Institute as attitudes or stereotypes that are activated unconsciously and involuntarily" (Flannery, 2015). Conflict is expected to happen in schools. Conflicts can have an array of simple stressors to rage that leads to aggression (Ozgan, 2016).

Research should be done to gain an understanding of how bias can be avoided by the education staff, and research into the causes of student adverse reactions (Bennett, M, Bennett, S, 2019). According to Bennett (2019) "We should no longer view disruptive behavior as intentional or planned", but instead find the reason for the adverse behavior and give each student with adverse reactions social-emotional assistance and training. The social-emotional training needed and given to students, should be reflected on and given by teachers who are trained and able to condense personal bias, leaving their personal bias out of their teacher-student relationships. Training to understand bias theory, differentiation, possible impact of family and background on each child's early development can help teachers develop a conscience plan to prevent bias from interfering in children's' education, whether that bias is from the teacher or from the student. 


\section{Literature Review}

A literature review is a method to assess a collection or body of research, and to address a research question. The purpose of this typical literature review is to identify "what is already known" (Harvard Graduate School of Education, 2020), thus looking to "identify questions this body of research does not answer", and to "Make a case for why further study of research questions is important...". The process followed begins with framing any research questions: How does bias influence conflicts between teachers and students? How can reflection and differentiation make a difference in the bias that influences teacher conflicts with students?

Included in this literature review is an investigation of obtainable resources (Reynolds, 2012) that address the bias involved in conflict between teachers and students. Relevant "bodies of literature" have been searched, and synthesized by dividing the review into four sections, and is followed by teacher perspectives, families and backgrounds, reflections, suggestions, and recommendations. The four sections as related to teacher reflection, identified in this literature review, include, bias theory, differentiation, possible impact of family and background on the child's early development, and conflict between teacher and student. "The literature review is an examination of credible literature from topics that are relevant to the subject of teacher bias" (Reynolds, 2012) involved in teacher reflections about teacher conflict with students.

\section{Bias Theory}

Much can be learned from literature a century ago, through today. "Literature discussing bias has been found dating as early as 1935 (Dollard) and as late as 2010" (Reynolds, 2012). Bias theory in this literature review, is defined and includes how bias influences teacher conflict with students, is subjugated by five areas; personal choice, emotions, situations children experience, slow approaches to learning, and teacher reflection.

A variety of daily choices for each teacher, impacts the classroom. Choices such as: "how to organize classrooms and curriculums, how to interpret students' behaviors, how to protect learning time, and so forth" (Danielson, 2009). "Academic achievement" is at risk due to the behaviors of both teachers and students (Bennett and Bennett, 2019). The teacher's role has real value and influence in the classroom. Teaching is the most valuable component in a student's development (Harvard College, 2019); of course, the teacher is in the place of teaching for the purpose of educating students. Teachers like any other person can be persuaded by personal choice, thus being influenced by their own bias'. "According to Swee-Choo (2008), people who are biased to others based on personal choice, show favoritism or unfair treatment" (Reynolds, 2012) creating possible distortions (Swee-Choo, 2008) in teaching practices, and creating slow approaches to learning and possible insincere teaching. Also creating possible bias, is outside factors that may be unrecognized with-in each classroom. Teacher can be influenced by unseen outside factors (Reynolds, 2012), thus impacting the teacher's behavior. Teachers need to also be aware that "children's performance in any situation can be altered because of the influences, emotions, or situations children experience" (Reynolds, 2012), and bias children experience, and hold themselves. Bias can be identified in most situations where people reside.

According to Dovidio (2011) bias can have two different attitudes, implicit and explicit. Explicit attitudes contain awareness, such as conscious or cognitive, can be deliberative, and incorporate social and personal values. While implicit attitudes are less extrinsic and include the unconscious, can become spontaneous and be habit forming, coming from direct and vicarious experience. "A Few Key Characteristics of Implicit Biases" are "pervasive". No one seems immune, "Everyone possesses them, even people with avowed commitments to impartiality such as judges" (Ohio State University, 2015) Implicit and explicit bias have overlapping traits that tend to reinforce each other. However, "Implicit biases are malleable. Our brains are incredibly complex, and the implicit associations that we have formed can be gradually unlearned through a variety of debiasing techniques" (Ohio State University, 2015) 
Unconscious bias is implicit, "It is important to note that biases, conscious or unconscious, are not limited to ethnicity and race" (University of California, n.d.). Conscience biases are explicit, responsibility bias'- "A number of situational and psychological factors have been shown to reduce or enhance responsibility biases" more likely in groups in which members are seen as a collective, but reduced when unpacking occurs and members are considered as individuals (Savitsky et al., 2005). Thus, remembering people as individuals instead of a group member, less explicit bias is present.

\section{Differentiation}

Differentiation tends to benefit a broad spectrum of student ability levels (Weselby, 2014), with "a substantial body of evidence indicates that student learning is multidimensional" (Blazar \& Kraft, 2017), giving rise to a need to give multi-dimensional instruction. A considerable positive impact on classroom function in both assessment and behavior can be made with corrective differentiation in the classroom. Differentiation can be organized in different ways. Teaching to each child's preferred learning style, giving one organizational method; or teachers can "Group students by shared interest, topic, or ability for assignments" (Welsby, 2014). Another method of differentiation can use formative assessment, "continually assessing and adjusting lesson content to meet students' needs" (Welsby, 2014).

Differentiation can help with classroom management. By giving each child what they need, the children will begin to feel safe, leading to creating and managing safe and accommodating environment (Welsby, 2014). "High-quality teachers are...expected not only to raise test scores but also to provide emotionally supportive environments that contribute to students' social and emotional development, manage classroom behaviors, deliver accurate content, and support critical thinking (Cohen, 2011; Lampert, 2001; Piant and Hamre, 2009). "As inclusive education grows, so too does the need for effective differentiated instruction strategies in the classroom. Differentiated instruction, while an important tactic for student success, requires some" reflective practice, "education and expertise to do well" (King University, on-line, 2020).

According to Weselby (2014), there are four ways to differentiate for student success. By using differentiation, behavior of each student will adjust. The first listed by Weselby, involves process, product, learning environment, and content examples. The content examples, includes; matching vocabulary words to definitions, reading a passage of text and answering related questions, thinking "of a situation that happened to a character in the story and a different outcome", differentiating "fact from opinion in the story", identifying an author's position and providing evidence to support this viewpoint. By either assigning different forms of content presentation or letting the children choose, content can be differentiated based on a child's learning style, or ability. Process choice can also be included in the differentiation of children and content. "Examples of differentiating" through process" can include, providing "textbooks for visual and word learners", and "Allow auditory learners to listen to audio books", and giving "kinesthetic learners the opportunity to complete an interactive assignment online" (Weselby, 2014). Examples of differentiating through product development can include, writing book reports of books read, encouraging visual learners "to create a graphic organizer of the story" just read, giving an opportunity for auditory learners to give an oral report and then differentiation for Kinesthetic learners can include building a diorama illustrating the story, or through dramatic play. Of course, a reflective perspective of including the environment leads to differentiation through the environment. Examples of differentiating through the environment can include; Breaking "some students into reading groups to discuss the assignment", allowing "students to read individually", and to "create quiet spaces where there are no distractions" (Weselby, 2014).

\section{Possible Impact of Family and Background on the Child's Early Development}

Addressing bias involved in teacher and student conflict includes addressing bias that students have been subjected to since birth. A child's early bias begins development with external and internal influences (Oxford 
University Press, 2020). Parents are their child's first teacher. "The most influential factors in a child's early life are their attachment relationships or the dynamics of their relationship with their parent or primary caregiver (Bennett and Bennett, 2019). Brain development is impacted by a child's first experiences (Harvard, 2020) providing for the growth of a child's own bias development. "A child with consistent parents and a developed prefrontal cortex learns that following adult expectations keeps them safe and helps them learn about the world" (Bennett, M and Bennet, S, 2019). Not only is there real physical and emotional change that transpires, but the learned behavior can be influenced (Gilleard and Higgs, 2015). When children learn to mistrust adults from their homes, it is a challenge for them to trust the adults in schools (Bennett, M and Bennet, S, 2019). "Students entering schools with secure attachments come with the expectation that the teacher will treat them with a similar level of respect and support they get at home" (Bennett and Bennett, 2019), thus creating a form of bias from the student directed to the teacher.

According to the CDC (2016) "The Adverse Childhood Experience Study found that by the time middle- and upper-class children turn 18, nearly two out of three children experienced trauma" (Bennett, M and Bennet, S, 2019). Trauma changing the physical development of several brain areas, also changes hormone levels, thus possibly influencing emotional response (Bennett and Bennett, 2019), leaving some teachers with-out knowledge of any reasons for outward behaviors, fending for themselves.

\section{Teacher Conflict with Students}

Conflict can originate from the unseen, and the misunderstanding of situations experienced in any teacher's or child's past, or current life experiences. There is a general belief that most children who are non-compliant, choose to be non-compliant (American Psychological Association, 2008). Although each choice may not be a conscience one and may be influenced by bias. As previously described, intrinsic and extrinsic influences can have an impact on the bias development of children (Oxford, 2020). This impact includes the possibility of trauma influences (Bennet and Bennett, 2019), or other non-trauma experiences. Life experiences do change brain development and emotional response (Bennett, M and Bennet, S, 2019), leading to possible teacher conflict with students.

A general belief of implicit bias, can lead to bias aimed from the teacher, towards the students (Flannery, 2015). The variables that begin teacher-student conflict can be many (Ozgan, 2015). "Although there is a great concern about the way a teacher manages student behavior, there is very little relevant data concerning teacher-student conflict", and reflective practice (Ciuladiene and Kairiene, 2017).

School's social climate and culture can be, "characterised not only by constructive but also by destructive interactions", (Ciuladiene and Kairiene, 2017). The "teacher-student relationships dominated by a conflict are negatively associated with student behavioral and affective engagement in learning" (Ciuladiene and Kairiene, 2017). Solving teacher-student conflict can be a challenge and a matter of needed training. The classroom teacher needs training, support, and empathy for the children in order to address conflict with-out bias. "Empathy is a key part of being a responsible and helpful community member at school and elsewhere" (Harvard University, 2018).

Reflection is a tool that effective teachers know how to use with the proper training and support. For example, many untrained teachers will ask things like, "what is wrong with this child?" (Bennett and Bennett, 2019) Instead, trained teachers should ask, "what has happened to this child and how can I help?" (Bennett and Bennett, 2019), beginning a problem-solving approach to solve teacher-student conflict. According to Ciuladiene and Kairiene (2017), "the least common approach was problem solving". With benefit of reflection, empathy, support and training, teachers can begin to establish a problem-solving approach that can lead other educators in finding solutions. 


\section{Conflict}

Conflict can be recognized between any persons who come in contact with each other. Teachers and students are not immune to this possibility. Conflict, "a normal, and even healthy, part of relationships. After all, two people can't be expected to agree on everything at all times. Since relationship conflicts are inevitable, learning to deal with them in a healthy way is crucial" (Helpguide.org, n.d.). The understanding of teachers needing to lead students through their own frustrations, have to take the form of strategy, understanding and example. Teachers need to find a strategy per differentiation for each student (Özgan, 2015) while setting the example of patience. Patience and understanding can take a role of counselor and researcher to understand reasons why a student may be self-destructive, or struggling. It is possible for students to subconsciously, work at creating their own environment of hostility because of the familiarity of it (Bennett and Bennett, 2019).

Even though, "...it is not possible to avoid all sources of conflict, it is in the best interests of the" classroom teacher "to recognize conflicts" . . and to take steps to nullify or mitigate those conflicts" (RREE, 1999-2016). By recognizing, and demonstrating how to handle conflict through example, patience and being in "...touch with your feelings" (Helpguide.org, n.d.), teachers can avoid such stress to prevent the issue of paying "attention to a limited number of emotions, you won't be able to understand your own needs" (Helpguide.org, n.d.), and the needs of your students.

\section{Dr Rebecca Reynolds' Reflections on Students and their Frustrations}

Differentiation can be so important when addressing bias that is involved in teacher conflict with students. Teaching in any classroom will most certainly give the experience of dealing with angry students, and likely students who have experienced trauma of some kind, or may have had limited training in emotional control. Student's many times will need guidance and examples of how to handle stress, anxieties, and emotional responses. Empathy and strategies must be relevant and in place to assist the students who struggle with their own frustrations. Teachers must be trained properly to understand how to perceive and handle, each child's unique emotional needs.

In this section Dr. Reynolds will discuss her reflection with-in a reflective cycle. This reflective cycle, as shown below, includes a pictorial representation of the method used to prevent biased descriptions and implementations, with proposed adjustments based on evaluations and assessments. By following the prescribed cycle, it will be possible to continually learn from one's own reflective practice, improving with time.

Describing one's own reflections about student's frustrations can only begin with one of two sources to pull information from; internal personal experience, and observational experience. Because reflecting on internal personal experience is limited to the passage of time, reflections based on observational experiences will be more valid with less limitations. Using an actual experience as an example, described below, as documented based on observation, with the use of the reflective cycle will be described and discussed. 


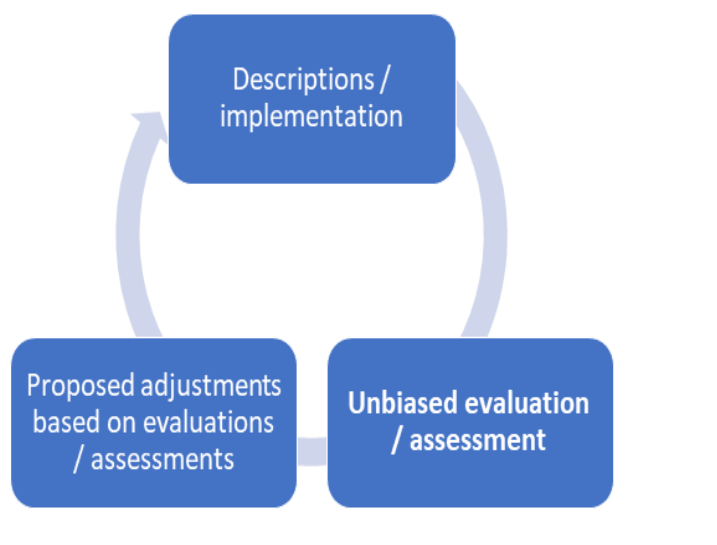

Unbiased Observation Descriptions/Implementations Example

Below is a description of an actual occurrence with a student whose name has been changed.

\section{Child: David}

\section{Age/grade: Kindergarten}

\section{Diagnosis / IEP: ADHD, Conduct Disorder}

David walked into the classroom looking down as he walked. David walked directly into the book shelf, swung his hands up hitting Colleen in the face with his fingers, turned and walked into the bathroom where he turned on the water in the sinks, then walked to the carpet and sat down. Once sitting down, he started to tap on the back of Colleen with one finger. Colleen moved about one inch forward, then David followed reaching and tapping Colleen's back again. The classroom aid entered the room where she stopped next to the classroom teacher. Aid asked Teacher, "How has David been so far this morning"? Teacher described David's behavior. Aid then walked towards David, whispered into David's ear, and reached for David's hand. David took Aid's hand, he walked with Aid to the bathroom where David turned off the water, then together they walked to Colleen where Aid asked David, "Why should you not batter Colleen?" David said, "Because you said it's not nice". David then stroked Colleen's hair, looked into Colleen's face, and whispered "Sorry". Aid and David then walked to the carpet to finish story time. Later that same day, during a conversation with David's eight-year-old sister, Aid found out that David's parents had a loud argument in front of the kids, concluding with dad leaving mom with no car in the morning.

\section{Evaluation / Assessment}

When documenting one's own observations, make sure to differentiate between the actual observations from the opinions and assessments. Work on making sure that opinions and personal bias is not written into the observations. This gives a clear objective path to move forward with an accurate assessment of children's needs, and improvements that can be made to one's own teaching methods. Once this "Objective observation" is written clearly, write the title "Subjective observation" with personal thoughts, opinions, and assessments. It is vital that professionalism is clear in the writing. By using this method of separating the subjective observation, or personal bias from objective observation, it is possible to continually learn objectively from one's own experiences. This method will also serve to create a timeline of improvement for David, as well as guide immediate teaching needs. An example of the Subjective Observation from the Objective Observation above is listed below: 


\section{Subjective Observation: David}

By looking over the documented objective observation and reflecting on the activities as planned, implemented, perceived and understood; Teacher will be able to document reflections and opinions about student progress, and any possible planned changes that could benefit the classroom in the subjective observation. This separation of assessment and opinion from fact helps to differentiate for individual and group needs of students. For example, Table 1 shows such differentiation in planned changes.

Table 1

\begin{tabular}{|c|c|}
\hline Subjective Observation (Reflection/Opinion) & Differentiation / Planned changes \\
\hline $\begin{array}{l}\text { David didn't seem angry as he entered the classroom, } \\
\text { he didn't have any outward angry behavior such as } \\
\text { yelling or stomping his feet. } \\
\text { By waiting for Assistant to enter the room, Teacher } \\
\text { encouraged David's behavior while Assistant was not } \\
\text { present. }\end{array}$ & $\begin{array}{l}\text { As David enters the room, Teacher is to acknowledge } \\
\text { him with a warm welcome, encouraging him to engage } \\
\text { in conversation. } \\
\text { Teacher is to keep in regular conversation with } \\
\text { Assistant and parents }\end{array}$ \\
\hline $\begin{array}{l}\text { David showed that he understood what Assistant } \\
\text { wanted him to do when she brought David to Colleen } \\
\text { by following through with apologizing. }\end{array}$ & $\begin{array}{l}\text { Special attention throughout each day (at a minimum of } \\
30 \text { minutes per day) will be spent on conversation } \\
\text { about feelings and reactions to the class as a whole, and } \\
\text { to David individually. }\end{array}$ \\
\hline $\begin{array}{l}\text { David's reason for not hurting another child was that } \\
\text { Assistant said it is not nice. David still has trouble } \\
\text { understanding that the reason needs to be internalized } \\
\text { with-in himself. }\end{array}$ & $\begin{array}{l}\text { Special attention will be spent on asking David } \\
\text { clarifying questions like: } \\
\text { David how does that make you feel? } \\
\text { How do you think she/he feels? } \\
\text { Assist David with the correct wording when needed }\end{array}$ \\
\hline David seems to trust Assistant & $\begin{array}{l}\text { Assistant should begin to communicate with parents } \\
\text { and Teacher in front of David so that David can } \\
\text { identify everyone who he can trust } \\
\text { Holding conversations and playing card/board games } \\
\text { with David, parents, Assistant and Teacher together }\end{array}$ \\
\hline $\begin{array}{l}\text { Teacher did not involve herself in David's activities. } \\
\text { Teacher also needs to help David. }\end{array}$ & $\begin{array}{l}\text { By Teacher helping with David on a regular basis, } \\
\text { Teacher can be available at times that Assistant is not } \\
\text { available. }\end{array}$ \\
\hline $\begin{array}{l}\text { Colleen didn't yell out, or complain. She simply moved } \\
\text { away. This shows that Colleen either understands that } \\
\text { David has trouble with self-control, or this doesn't } \\
\text { bother her. }\end{array}$ & $\begin{array}{l}\text { Encourage Colleen to use her words and communicate } \\
\text { with David to "Please stop" when David's behaviors } \\
\text { affect her }\end{array}$ \\
\hline
\end{tabular}




\section{Proposed Differentiation Based on Evaluations / Assessments}

Reflecting on new information or how to scaffold that new information into a current classroom, should always be completed by having a plan of action. Adjustments needed to ensure that conflict is not sparked between David and Teacher, or David and Assistant needs to include added team effort between Parent(s), Teacher, and Assistant. It is only by using teamwork and communication within the circle of David's primary adults, that real change, and preparation can happen. For example, by using teamwork, on days when Assistant is unable to be present, Teacher will be able to effectively work with David. The second suggestion is to encourage family counseling for extra support to give parents real tools and guidance to assist David to learn to internalize how he affects other people. Invite parents to volunteer in the classroom as much as they are able. This can help parents understand how to handle David's needs by observing the teaching staff.

Be sure to involve all children who are impacted by David's behavior. In the case of this observation, include Colleen. Talk with Colleen ensuring her that the teaching staff are available to help her if she needs help. Also, lead activities with all of the students in group times that address how to react to others having behavior trouble.

\section{Recommendations and Conclusions}

Further phenomenological research on teacher and student opinion relating to how bias impacts teacher-student conflict should be conducted in a current day environment and continued for further assessment value, scaffolding new information as it presents itself. Creating phenomenological case studies of different schools can give detailed information of possible further needed research.

Recommendations based on the entirety of this work, and functional recommendations based on the current value of available research findings, should begin with the complete understanding that, "We should no longer view disruptive behavior as intentional or planned" (Bennett and Bennett, 2019). Teachers need to patiently teach social-emotional skills to the children with developmentally appropriate activities in a "safe relational environment". Teaching children how to understand, and effectively react to different situations have been found to be more useful than other consequence "harsh disciplinary policies" (Bennett and Bennett, 2019). The developmentally appropriate activities combined with understanding that, "a trauma that haunts one child throughout the rest of their life may serve only as a minor setback to another" (Bennett and Bennett, 2019). Taking into consideration that a child's over reaction to stimuli, can ultimately encourage a fear-based reaction (Bennett and Bennett, 2019) the child uses as a survival response, can help a teacher put the child's reaction into perspective. This perspective should accelerate into reflection on how to help this child through possible crises.

Reflection, bias and discovery may be an influencing factor in the daily choices that impact possible conflict with students. According to Flannery (2015), there are steps that can be taken to mitigate and interrupt implicit bias. These steps include; awareness, reflectiveness, and the consideration of classroom data. Then, adding to Flannery's list, a developed relationship between teacher and student, can change teacher perspectives. Once student perspectives and values are understood and accepted, a relationship that assists in preventing conflict between teacher and student can be developed.

The social-emotional training needed and given to students, should be given by teachers who are able to condense personal bias, leaving their personal bias out of their teacher-student relationships. "What's important to know about implicit biases is that, once people are made aware of them, those biases can be successfully addressed" (Flannery, 2015). Educators who work with their students to train them for social-emotional needs, should take into consideration that, "trauma is not a life sentence if help arrives in a timely and appropriate manner" (Bennett and Bennett, 2019).

Educators engaging in intentional reflective practice has gained momentum in recent years. While it has been hailed by many practitioners in the field, (Farrell, 2013; Killion and Todnem, 1991), it was LaPrade, Gilpatrick, 
and Perkins (2014) who highlighted how intentional reflection by teachers had a positive impact on teaching. The processes developed help teachers gain insight on ways to enhance academic learning, an important step in teacher development as confirmed by Von Dras (2008). Keeping in mind the attention focused on teachers' performance, accountability measures, and new teacher evaluation tools, Furtado and Anderson (2012), remind us about the necessity of creativity when teachers engage in planning, implementing and assessing learning opportunities. Reflective practice, along with "a harmonious relationship between students and teachers based on mutual respect, understanding, kindness and cooperation is essential for a positive school climate and the success of education" (Ciuladiene and Kairiene, 2017).

\section{Reference}

American Psychological Association (2008) Stress in America Retrieved from https://www.apa.org/news/press/releases/2008/10/stress-in-america.pdf

Bennett, M, Bennett, S (2019) Trauma-Sensitive Early Education, Helping Pre-Scholl \& Elementary Students Thrive!

Blazar, D. \& Kraft, M. (2017). Teacher and teaching effects on students' attitudes and behaviors. Educational Evaluation and Policy Analysis, 39(1), 146-170

Bridgewater State University. (May 1, 2015). 4.2 Thesis Submitted in Partial Fulfillment of the Requirements for the Degree of Master of Arts in Teaching English for Students of Other Languages Conclusion. 52-54 Retrieved from https://vc.bridgew.edu/cgi/viewcontent.cgi?referer=https://search.yahoo.com/\&httpsredir=1\&article=1020\&cont ext=theses

Chamness Miller, P., \& Mikulec, E. A. (2014). Pre-Service Teachers Confronting Issues of

Diversity Though a Radical Field Experience. Multicultural Education, 21(2), 18-24.

Ciuladiene, G, \& Kairiene, B (2017). The Resolution of Conflict between Teacher and Student: Studentsí Narratives- Journal of Teacher Education for Sustainability, vol. 19, no. 2, pp. 107ñ120, 2017 Retrieved from https://files.eric.ed.gov/fulltext/EJ1218148.pdf

Dollard, J. (1935). A method for the sociological study of infancy and preschool childhood. Journal of Educational Sociology, 9(2), 88-97. Retrieved from SocINDEX with Full Text database.

Debnam, K. J., Pas, E. T., Bottiani, J., Cash, A. H., \& Bradshaw, C. P. (2015). An Examination Of The Association Between Observed And Self-Reported Culturally Proficient Teaching Practices. Psychology In The Schools, 52(6), 533-548. doi:10.1002/pits.21845

Dovidio, J- (2011) Implicit vs. Explicit Attitudes, Biases, and Stereotypes- Retrieved from: http://conference.novaresearch.com/srdh/presentations/Dovidio.pdf

Flannery (2015) When Implicit Bias Shapes Teacher Expectations- retrieved from: http://neatoday.org/2015/09/09/when-implicit-bias-shapes-teacher-expectations/

Gershenson, Seth, Stephen B. Holt, and Nicholas W. Papageorge. (2015). "Who Believes in Me? The Effect of Student-Teacher Demographic Match on Teacher Expectations." Upjohn Institute Working Paper 15-231. Kalamazoo, MI: W.E. Upjohn Institute for Employment Research. https://doi.org/10.17848/wp15-231

Danielson, C. (2013). Framework for teaching evaluation instrument.

http://focus.teachscape.com/pdf/FrameworkForTeaching2013.pdf

http://teachscape.vo.llnwd.net/o36/u/production/content/downloads/2014_FfTEI_D1.pdf

Gay, G. (2010). Culturally responsive teaching: Theory, research, and practice, 2nd ed. New York: Teachers College Press

Gilleard, C Higgs, P (2016) Connecting Life Span Development with the Sociology of the Life Course: A New Direction Sociology. 2016 Apr; 50(2): 301-315. Published online 2015 May 12. doi: $10.1177 / 0038038515577906$

Harvard College (2019) Center for Education and Policy Research, Harvard University Retrieved from: https://cepr.harvard.edu/teacher-effectiveness 
Harvard University Graduate School of education (2018) For Educators: How to Build Empathy and Strengthen Your School Community Retrieved from https://mcc.gse.harvard.edu/resources-for-educators/how-buildempathy-strengthen-school-community

Harvard Graduate School of Education. (October 28, 2020). A Literature Review: A Research Journey. Retrieved from https://guides.library.harvard.edu/literaturereview

Harvard University. (2020). Center on the Developing Child. In Brief: The Impact of Early Adversity on Children's Development.

$\begin{array}{llllll}\text { Helpguide.org } & \text { (n.d.) } & \text { Conflict } & \text { Resolution } & \text { Skills } & \text { Retrieved }\end{array}$ https://www.edcc.edu/counseling/documents/Conflict.pdf

King University on-line (2020) How Differentiated Instruction Strategies Impact Classroom Learning Retrieved from https://online.king.edu/news/differentiated-instruction-strategies/

Howard, G. (2015). We can’t lead where we won’t go: An educator's guide to equity.

Knight, S. and Gilpatrick, M. (2019). ELL Families: Myths, Truths and Strategies for Engagement, Journal of English Learner Education: Vol. 9 : Iss. 1, Article 4. Available at: https://stars.library.ucf.edu/jele/vol9/iss1/4

Ohio State University (2015) Understanding Implicit Bias- Retrieved from: http://kirwaninstitute.osu.edu/research/understanding-implicit-bias/

Nieto, S. (2013). Finding joy in teaching students of diverse backgrounds: Culturally responsive and socially just practices in U.S. classrooms. Portsmouth, NH: Heinemann Publishers.

Ozgan, H. (2016). The Usage of Domination Strategies in Conflicts Between the Teachers and Students: A Case Study. Vol. 11(4), pp. 146-152, 23 February, 2016 DOI: 10.5897/ERR2015.2542 Article Number: 9EDD36557172 ISSN 1990-3839

Resources for Research Ethics Education (RREE) (1999-2016) What is a Conflict of Interest? What Should I do? Retrieved from http://research-ethics.org/topics/conflicts-of-interest/

Reynolds, RJ (2012) A PHENOMENOLOGICAL CASE STUDY: TEACHER BIAS EFFECTS ON EARLY EDUCATION ASSESSMENTS (Doctoral Dissertation)- Retrieved from ProQuest- (ED554902)

Schulz, L. L., Hurt, K., \& Lindo, N. (2014). My Name Is Not Michael: Strategies for Promoting

Cultural Responsiveness in Schools. Journal Of School Counseling, 12(2),

Swee-Choo, P. (2008). Teaching Practices that Hinder the Deep Approaches to Learning of Twinning Programme Students in Malaysia: A Qualitative Perspective. Asia-Pacific Education Researcher, 17(1), 63-73. Retrieved from Education Research Complete database.

University of Kansas. (1994-2020). Section 1. Understanding Culture and Diversity in Building Communities. Why is Culture Important. 